\title{
Placas y pápulas erosivas en los pliegues
}

\section{Erosive plaques and papules in folds}

\section{Eugenia Miraglia ${ }^{1}$, Eliana Maribel Gerez ${ }^{2}$, María Victoria Garritano ${ }^{3}$ y María Roxana Maradeo ${ }^{4}$}

1 Médica Instructora de Residentes

2 Médica Jefa de Residentes

3 Médica de Planta

${ }^{4}$ Médica Jefa del Servicio

Servicio de Dermatología, HIGA General San Martín, La Plata,

Provincia de Buenos Aires, Argentina.
Contacto del autor: Eugenia Miraglia

E-mail: eugemiraglia9@gmail.com

Fecha de trabajo recibido: 3/8/2020

Fecha de trabajo aceptado: 28/9/2020

Conflicto de interés: las autoras declaran que no existe conflicto de interés.

Dermatol. Argent. 2020, 26 (3): 133-135

\section{CASO CLÍNICO}

Una mujer de 23 años, con antecedentes de infección por HIV diagnosticada en 2012, que seguía un tratamiento antirretroviral errático, el cual reinició hacía 3 meses, consultó a nuestro servicio por lesiones cutáneas distribuidas en los pliegues, de un mes de evolución.

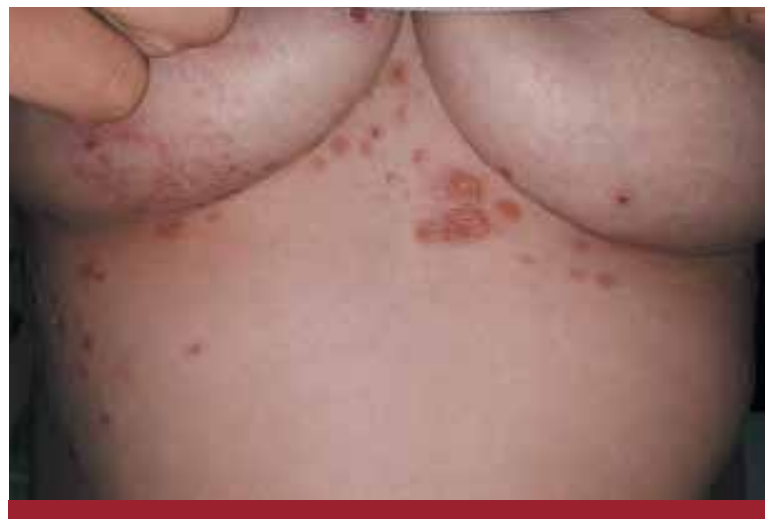

F0TO 1: Pápulas y placas eritematosas, algunas con un centro erosivo, localizadas en el pliegue submamario.

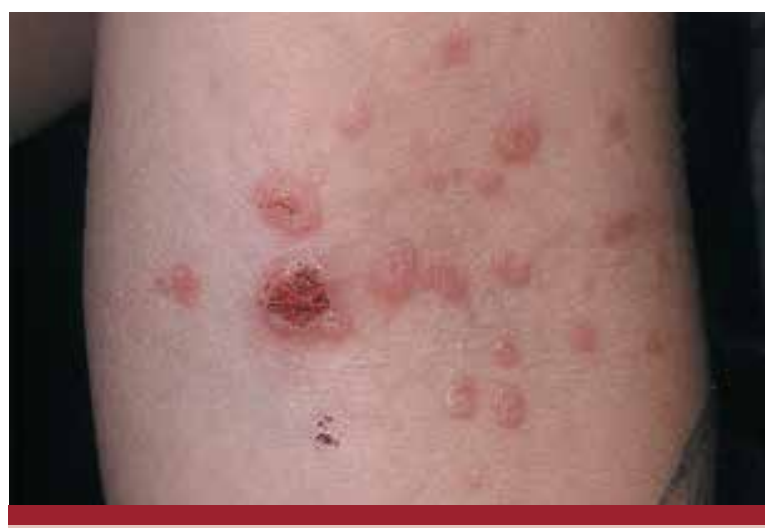

FOTO 2: Pápulas eritematosas de superficie brillante y algunas con un centro erosionado, ubicadas en el pliegue antecubital.
En el examen físico presentaba pápulas y placas eritematosas, algunas con un centro erosivo y de borde bien delimitado, que comprometían los pliegues submamario, axilares, inguinales y antecubitales (Fotos 1, 2 y 3). La paciente refería ardor y dolor, además de un

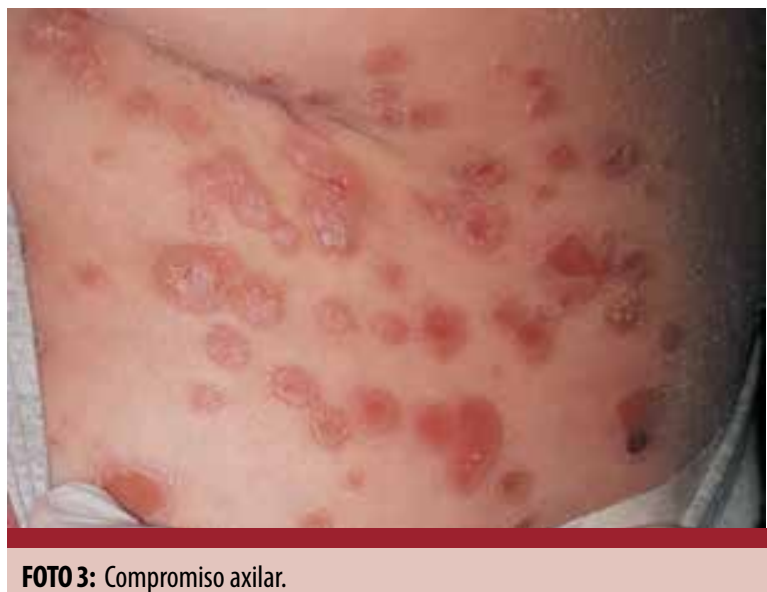

FOTO3: Compromiso axilar.

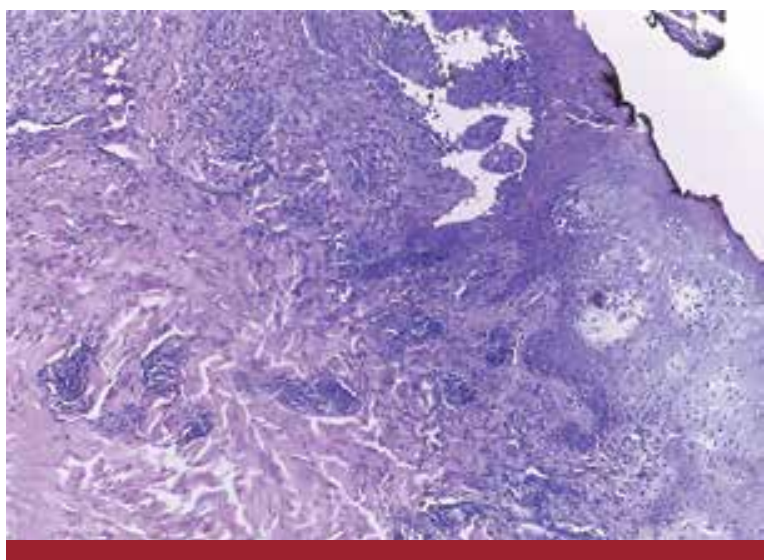

F0T0 4: Infiltrado inflamatorio dérmico mixto perivasculary perianexial (HyE, 10X). 
cuadro de repercusión general con astenia, adinamia y pérdida de peso. Las mucosas estaban respetadas y no tenía adenopatías.

Se solicitó un laboratorio general con pruebas serológicas para virus hepáticos, VDRL, nueva carga viral y recuento de CD4. Se realizó una biopsia para estudio histopatológico, que informó: epidermis con acantosis, paraqueratosis, marcada espongiosis, exocitosis leucocitaria y vacuolización de la membrana basal. En la dermis, un infiltrado inflamatorio mixto perivascular y perianexial con linfocitos, histiocitos, células plasmáticas y neutrófilos (véase Foto 4).

\section{DIAGNÓSTICO}

Sífilis secundaria: condilomas planos.

\section{COMENTARIO}

La síflis es una enfermedad infecciosa sistémica causada por una espiroqueta, Treponema pallidum, que se contagia fundamentalmente por contacto sexual y por transmisión vertical durante el embarazo y a través del canal de parto. Representa un problema de salud mundial, con 12 millones de personas infectadas por año ${ }^{1,2}$.

La sífilis secundaria cursa con lesiones cutaneomucosas que aparecen en brotes y tienden a resolverse dentro del primer año del contagio. Las lesiones características de esta etapa de la enfermedad se denominan sifilides y se presentan en múltiples variedades: maculosas, papulosas, foliculares, papulonecróticas, en placas, vegetantes, anulares, ulceradas, hipopigmentadas o hiperpigmentadas, parches alopécicos, etc. Este gran polimorfismo lesional es el que le ha valido a la síflis la denominación de "la gran simuladora” y el médico debe mantener un alto índice de sospecha, ya que se pueden confundir fácilmente con lesiones propias de otras patologías ${ }^{1-3}$.

Cuando las sifilides asientan en los pliegues cutáneos o cutaneomucosos, zonas húmedas o de roce, se denominan condilomas planos. Son lesiones altamente contagiosas, con una gran carga de treponemas y aparecen hasta en el $10 \%$ de los casos de sífilis secundaria ${ }^{4}$.

Clínicamente, consisten en pápulas o placas múltiples sobreelevadas, hipertróficas y de tamaño variable. La superficie suele estar erosionada o macerada y emanan un olor característico sui generis. A veces, se cubren de una película de color blanco-grisáceo, producto del carácter exudativo de las lesiones. Si bien casi siempre son asintomáticas, algunos pacientes pueden referir ardor, prurito o incluso dolor ${ }^{4}$.

Treponema pallidum es un microorganismo que crece mejor en un ambiente con baja tensión de oxígeno, por eso, los pliegues y las zonas de oclusión son los sitios más favorables para su desarrollo ${ }^{4}$. Los pliegues afectados con mayor frecuencia son el interglúteo, el vulvar, el perianal y el inguinal. En el escroto también pueden encontrarse estas lesiones. La localización en los pliegues submamario, auricular, axilar e interdigital y en el ombligo, si bien se observó, es excepcional ${ }^{4}$.Fiumara describió la localización axilar en una mujer y Hua et ál. presentaron el caso de una paciente con condilomas planos en las axilas, los pliegues inguinales y la región perianal ${ }^{5,6}$. Cabe aclarar que los casos mencionados correspondieron a pacientes inmunocompetentes, a diferencia de la paciente estudiada que, además, presentaba compromiso de los pliegues antecubitales. No hemos encontrado hasta ahora, en la literatura especializada, ningún caso con esa localización.

Muchos autores consideran que la mala higiene, la hiperhidrosis y el antecedente de intertrigo micótico son factores predisponentes para la aparición de condilomas planos en los pliegues 4 .

La coinfección con HIV y sífilis es frecuente y puede alterar el curso clásico de esta última, con manifestaciones clínicas atípicas y más agresivas o extensas. Se recomienda, al realizar el diagnóstico de sífilis, solicitar serología para el $\mathrm{HIV}^{\top}$. En el caso de la paciente, el diagnóstico de infección por HIV era conocido y sus valores de CD4, menores de 200 cél. $/ \mathrm{mm}^{3}$, con alta carga viral, lo que pudo haber influido en la presentación clínica tan extensa y florida.

El cuadro dermatológico muchas veces se acompaña de un síndrome de repercusión general con fiebre, astenia, mialgias, artralgias y pérdida de peso, como sucedió en nuestro caso. Además, es posible el compromiso de órganos internos, como la afectación renal con síndrome nefrótico o síntomas neurológicos por neurosífilis ${ }^{4,8}$.

Para el diagnóstico de sífilis secundaria se cuenta con diversos métodos de estudio, directos o indirectos. El campo oscuro es de gran utilidad para detectar treponemas en los condilomas, debido a la alta carga que tienen en estas lesiones. En la mucosa oral o anal, este método podría dar falsos positivos, ya que en estas regiones se encuentran treponemas saprofíticos, no patógenos, difíciles de distinguir de Treponema pallidum ${ }^{8}$. Dada la alta concentración de anticuerpos durante el secundarismo, la sensibilidad de las pruebas serológicas es muy alta, cercana al $100 \% \%^{3,10}$. En el caso comunicado, la VDRL fue de 64 dils y la prueba treponémica (TP-HA) fue positiva. En el estudio histopatológico se puede encontrar un infiltrado inflamatorio perivascular con plasmocitos. Si bien no siempre es necesaria la realización de una biopsia cutánea, ante la duda diagnóstica puede ser una herramienta útil, en especial para descartar otras patologías 4 .

Los diagnósticos diferenciales de sífilis secundaria planteados habitualmente son: farmacodermia, pitiriasis rosada, pitiriasis liquenoide y varioliforme aguda y exantemas virales, entre otros. En los pacientes con infección por 
el HIV, se deben tener presentes también las infecciones oportunistas ${ }^{7}$. En nuestro caso, además, se incluyeron patologías que afectan los pliegues, como pénfigo vegetante, intertrigo candidiásico y eccema herpético.

La penicilina es el tratamiento de elección y el único antibiótico que, hasta la fecha, no ha generado resistencia y que permite una rápida curación. En la síflis temprana, se indica una dosis única de 2,4 millones de unidades de penicilina $G$ benzatínica por vía intramuscular. En la sífilis latente tardía o síflis terciaria, están indicadas tres dosis separadas por una semana ${ }^{1}$. En la paciente del caso comentado, se instauró el tratamiento con una dosis de penicilina y se observó una notable mejoría a las 72 horas de su aplicación.

\section{CONCLUSIONES}

La sífilis secundaria tiene una gran riqueza semiológica y evoca múltiples diagnósticos diferenciales, lo que obliga al dermatólogo a mantener un alto índice de sospecha, dada su elevada prevalencia. El reconocimiento precoz de los condilomas planos es fundamental para controlar la cadena epidemiológica, ya que son lesiones altamente infectantes. Es indispensable recordar que pueden hallarse en localizaciones inusuales, como los pliegues axilares, submamarios y antecubitales. Además, la coinfección con el HIV puede alterar el curso clínico de la sífilis y, en estos casos atípicos, el diagnóstico se torna más dificultoso.

report. Int J Dermatol 2008:47;56-58.

7. Pérez-Pérez $L$, Cabanillas $M$, Ginarte $M$, Sánchez-Aguilar $D$, et ál. Sífilis maligna en un paciente con infección por el VIH. Actas Dermosifiliogr 2007;98:351-354.

8. Pérez Cortés S, Novales Coloma J, Moreno Agraz G. Secundarismo sifilítico en pacientes inmunocompetentes, comunicación de dos casos. Rev Cent Dermatol Pascua 2005;14:152-155.

9. Bermejo A, Monticelli A, Famiglietti A, Bouzas B, et ál. Primer consenso de diagnóstico, tratamiento y prevención de las enfermedades de transmisión sexual. [en línea], Comisión de sida y ETS de la Sociedad Argentina de Infectología; 2011. Disponible en: <https://drive.google.com/file/d/1vqw7usdeyo5 fkjxwb239f8pudq9mbdur/view> [Consulta: julio 2020].

10. Medina Castillo D, Mora Ruiz S. Sífilis secundaria. Comunicación de un caso. Rev Cent Dermatol Pascua 2002;1 1:14-17.

6. Hua H, Zhu X, Yang L, Li M, etál. Multiple condylomata lata: a case

\section{DERMATÓLOGOS JÓVENES}

* ACTUALIZACIÓN BIBLIOGRÁFICA: Inmunocriocirugía, una alternativa terapéutica en los carcinomas basocelulares invasores

María Belén Mariucci Vázquez

Unidad de Dermatología, Hospital General de Agudos Dr. Cosme Argerich, Ciudad Autónoma de Buenos Aires, Argentina

El carcinoma basocelular es la neoplasia malig- tratamiento, se realizan dos ciclos de criocirugía de na más prevalente y una patología muy frecuente de consulta dermatológica.

La cirugía convencional y la cirugía micrográfica de Mohs representan la primera opción de tratamiento, pero se cuenta con numerosas alternativas de segunda línea como el tratamiento tópico con 5-fluorouracilo o con imiquimod, la criocirugía y la terapia fotodinámica, con menores tasas de respuesta y mayores tasas de recidiva.

La inmunocriocirugía consiste en la aplicación diaria de un inmunomodulador, como el imiquimod al $5 \%$ en crema durante 2 semanas, sobre la lesión, con un margen de $0,5 \mathrm{~cm}$. En el día 14 de
15 segundos cada uno en el área tratada y luego se continúa con la aplicación del imiquimod durante 3 semanas más (5 semanas de tratamiento total).

La tasa de respuesta completa es mayor del $95 \%$ en los carcinomas basocelulares invasores (no superficiales), ampliamente superior a la de la monoterapia con imiquimod o la criocirugía y comparable con el tratamiento quirúrgico. La tasa de recidiva no llega al $10 \%$ a los 5 años en las lesiones menores de $2 \mathrm{~cm}$.

Los beneficios de este tratamiento se deben a que el imiquimod generaría un aflujo de células dendríticas antes de la liberación de antígenos tumorales con la criocirugía, y la consecuente pre- sentación antigénica y producción de anticuerpos específicos que destruyen el tumor. El mantenimiento de la respuesta inmunitaria en el tiempo con la finalidad de la eliminación total de la lesión se produce con la aplicación del imiquimod durante 3 semanas más después de la criocirugía.

Si bien los estudios son escasos y la técnica empleada dificulta la realización de ensayos doble ciego con grupo control, se concluye que la inmunocriocirugía constituiría una alternativa de tratamiento eficaz y de bajo costo en los tumores inoperables 0 en los pacientes que rechazan la cirugía, incluso ante lesiones de gran tamaño y en localizaciones con alto riesgo de recidiva.

\section{BIBLIOGRAFÍA}

- Gaitanis G, Bassukas ID. Immunocryosurgery for non-superficial basal cell carcinoma: a prospective, open-label phase III study for tumours < 2 cm in diameter. Acta Derm Venereol 2014;94:38-44.

- Gaitanis G, Bassukas ID. Immunocryosurgery for non-superficial basal cell carcinomas $\leq 20 \mathrm{~mm}$ in maximal diameter: Five-year follow-up. J Geriatr Oncol 2019;10:475-478. 